\title{
Role of maternity waiting homes in the reduction of maternal death and stillbirth in developing countries and its contribution for maternal death reduction in Ethiopia: a systematic review and meta- analysis
}

Tegene Legese Dadi ${ }^{1,3^{*}}$, Bayu Begashaw Bekele ${ }^{1}$, Habtamu Kebebe Kasaye ${ }^{2}$ and Tadesse Nigussie ${ }^{1}$

\begin{abstract}
Background: Every family expect to have a healthy mother and new born baby after pregnancy. Especially for parents, pregnancy is a time of great anticipation. Access to maternal and child health care insures safer pregnancy and its outcome. MWHs is one the strategy. The objective was to synthesize the best available evidence on effectiveness of maternity waiting homes on the reduction of maternal mortality and stillbirth in developing countries.

Methods: Before conducting this review non-occurrences of the same review is verified. To avoid introduction of bias because of errors, two independent reviewers appraised each article. Maternal death and stillbirth were the primary outcomes. Review Manager 5 were used to produce a random-effect meta-analysis. Grade Pro software were used to produce risk of bias summary and summary of findings.

Result: In developing countries, maternity waiting homes users were $80 \%$ less likely to die than non-users (OR $=0$. $20,95 \% \mathrm{Cl}[0.08,0.49])$ and there was $73 \%$ less occurrence of stillbirth among users (OR $=0.27,95 \% \mathrm{Cl}[0.09,0.82]$ ). In Ethiopia, there was a $91 \%$ reduction of maternal death among maternity waiting homes users unlike non-users $(\mathrm{OR}=0.09,95 \% \mathrm{Cl}[0.04,0.19])$ and it contributes to the reduction of $83 \%$ stillbirth unlike non-users $(\mathrm{OR}=0.17,95 \%$ $\mathrm{Cl}[0.05,0.58])$.
\end{abstract}

Conclusion: Maternity waiting home contributes more than $80 \%$ to the reduction of maternal death among users in developing countries and Ethiopia. Its contribution for reduction of stillbirth is good. More than $70 \%$ of stillbirth is reduced among the users of maternity waiting homes. In Ethiopia maternity waiting homes contributes to the reduction of more than two third of stillbirths.

Keywords: Maternity waiting homes, MWHs, Maternal mortality, Stillbirth, Developing countries, Ethiopia, Maternal death

\footnotetext{
* Correspondence: tege2004@gmail.com; tegegnlegesse@mtu.edu.et

${ }^{1}$ Department of public health, Collage of Health Science, Mizan-Tepi

University, Tepi, Ethiopia

${ }^{3}$ Mizan Teferi, Ethiopia

Full list of author information is available at the end of the article
}

(c) The Author(s). 2018 Open Access This article is distributed under the terms of the Creative Commons Attribution 4.0 International License (http://creativecommons.org/licenses/by/4.0/), which permits unrestricted use, distribution, and reproduction in any medium, provided you give appropriate credit to the original author(s) and the source, provide a link to the Creative Commons license, and indicate if changes were made. The Creative Commons Public Domain Dedication waiver (http://creativecommons.org/publicdomain/zero/1.0/) applies to the data made available in this article, unless otherwise stated. 


\section{Background}

Pregnancy is a time of great anticipation to have healthy baby and mother after pregnancy. Experiencing maternal death and stillbirth in the final stages of pregnancy is unfortunate for families [1]. To make pregnancy and its outcome safer, every woman should have access to maternal and child health care services during pregnancy, delivery and a period after delivery [2]. As the recommendation of $\mathrm{WHO}$, improvement of obstetric care services can be accomplished by the following three methods: "1. Providing health care services for mothers in need - "flying squads"”, "2. Making favourable condition for mothers who need medical services - emergency transport", and "3. Making health care services more accessible to women [2]. The third solution, needs extensive expenditure on health service, including expanded skilled human resources, which is difficult for developing countries [2, 3].

Many women in low and middle income countries face the challenges of inaccessibility of obstetric care in rural and urban areas. Even where services are available the facilities are unequipped [2]. Rural women are 3.572 times more likely to die because of pregnancy or delivery than women who came from urban areas with 95\% CI (1.001, 6.726). This might be rural females do not utilize maternal health services due to different reasons. As a result they may face high obstetric complications [4].

To minimize these problems, developing countries used MWH (maternity waiting homes) as an alternative to increase accessibility of obstetric care services. MWH are homes built in the compound or near to health facilities that provides standard medical and emergency obstetric care services. This is the easiest way to decrease the complication related to child birth through avoiding the second delay. It decreases barriers, which includes: distance, geography, transport, cost of transport and communication between referral points, that inhibit access to service, $[2,3,5]$.

Globally low and middle income countries contribute about $99 \%$ of maternal death in 2015, from this sub-Saharan Africa accounts for 66\% of maternal death which is discriminately high [6]. In 2015 the estimated global stillbirth was 18.4 per 1000 births, it was decreased by $25 \%$ from that of 2000 . In the same year, in sub-Saharan Africa it was decreased by $19 \%$, which was low progress [6]. Low and middle income countries contributes $98 \%$ of stillbirths; sub-Saharan Africa and South Asia share about 77\% [7]. Majority of losses related to pregnancy and child birth can be prevented through providing high quality and evidence based services [1].

According to EWEC technical workstream working group, by 2030 from 2010, all countries have to decrease MMR (maternal mortality rate) by a minimum of two thirds. In 2030 the target for the globe is $<70$ per
100,000 live births, but no country have to have a MMR of more than 140 per 100,000 live births. By 2030, the maximum stillbirth's rate is $<=12$ per 1000 live births for every country $[8,9]$. To achieve these targets each country has to work towards minimizing barriers of accessing quality maternal and child health care services. Therefore, planners should analyse their contextualised problems, researching available services, and implementation of rational framework for prioritizing and scaling up of essential services $[8,9]$.

\section{Research gaps identified}

There is one scoping review by Julie M. Buser et al. which shows new born outcomes of maternity waiting homes. This review doesn't appraise the quality of evidence and doesn't provide evidences of effectiveness of MWHs, it only narrate the available researches [10]. The systematic review on the Cochrane Review published in 2012 didn't include any randomized controlled studies and did not perform meta-analyses. It provides limited information on the potential benefit of MWH [11]. Thus, it is essential to prove efficacy of MWH through systematic reviews and meta-analysis.

In addition to the above reasons, the WHO 2015 endorsements on "health promotion interventions for maternal and newborn health states that there is a research gap on identifying efficacy of MWH." So there is a need for a study whether the MWH effectively improves birth outcomes or not [3].

\section{Objective of this review}

The objective of this review was to systematically identify, appraise and synthesize the best available evidence on effectiveness of MWHs on the reduction of maternal mortality and stillbirth in developing countries.

\section{Research questions}

Is constructing MWHs in developing countries is effective in decreasing maternal death and stillbirth?

How much MWHs kick in to the reduction of maternal death and stillbirth in Ethiopia?

\section{Methods}

\section{Search strategy}

Prior to conducting this review different databases, which publish reviews, was searched in 2017 G.C to verify the absence of antecedent reviews or protocols. The searched databases were: the Joanna Briggs Institute Database of Systematic Reviews and Implementation Reports (JBI- DSRIR), the Cochrane Database of Systematic Reviews, the Campbell Collaboration library, the National Health Centre Reviews and Dissemination databases, Evidence for Policy and Practice Information (EPPI-Centre). The search was using 
keyword and index search terms: Maternity waiting homes and maternity waiting areas with maternal death and stillbirth.

Except one review by Van Lonkhuijzen L. et al. from Cochrane Database of Systematic Reviews, no review is conducted as well as no protocol is developed. The objective of the study by Van Lonkhuijzen L. et al. was to see the effect of MWHs on maternal outcome using only clinical trials study. This review did not get any clinical trials and no result is provided by the review [11]. A scientific literature search from AJOL, PubMed, Google scholar, EMBASE, Ovid and Scopus databases was conducted from March - June 2017 GC using different search terms, which is listed in Additional file 1. Gray literatures were searched from Google and Google scholar, the largest store of gray literatures.

In addition, literatures were searched from research gate. For additional studies that may have been missed in the electronic search, cross reference was undertaken using the reference lists of all identified articles. Articles identified from variety sources were assessed for importance as per the objective of the study. All authors participated in searching each database. An abstract and full report was captured that meet the inclusion criteria.

\section{Inclusion and exclusion criteria}

The criteria for inclusion in the review includes quantitative research reports on effectiveness of MWHs on the decreasement of maternal death and stillbirth. In addition to the above mentioned, articles performed in developing countries and published in the English language are the criteria. We don't have a limitation on starting time of paper publication. Articles were excluded, if they are pure qualitative research, if data not presented for a comparator, if no data presented for the desired outcome, editorials and short commentaries.

\section{Selection of articles}

Study selection was conducted by all authors independently. The selection process was first started by avoiding duplicates using Mendeley Desktop reference manager. Next reviewing the titles and abstracts of all collected literatures were performed. Literatures with unrelated title and abstract were excluded. All relevant articles were considered for full review. When there were disagreements in the grouping of articles, decision was made by discussion and by reviewing the articles together.

Besides above mentioned inclusion criteria's, each paper that meet the inclusion criteria are critically reviewed by two independent reviewers for a single stud for

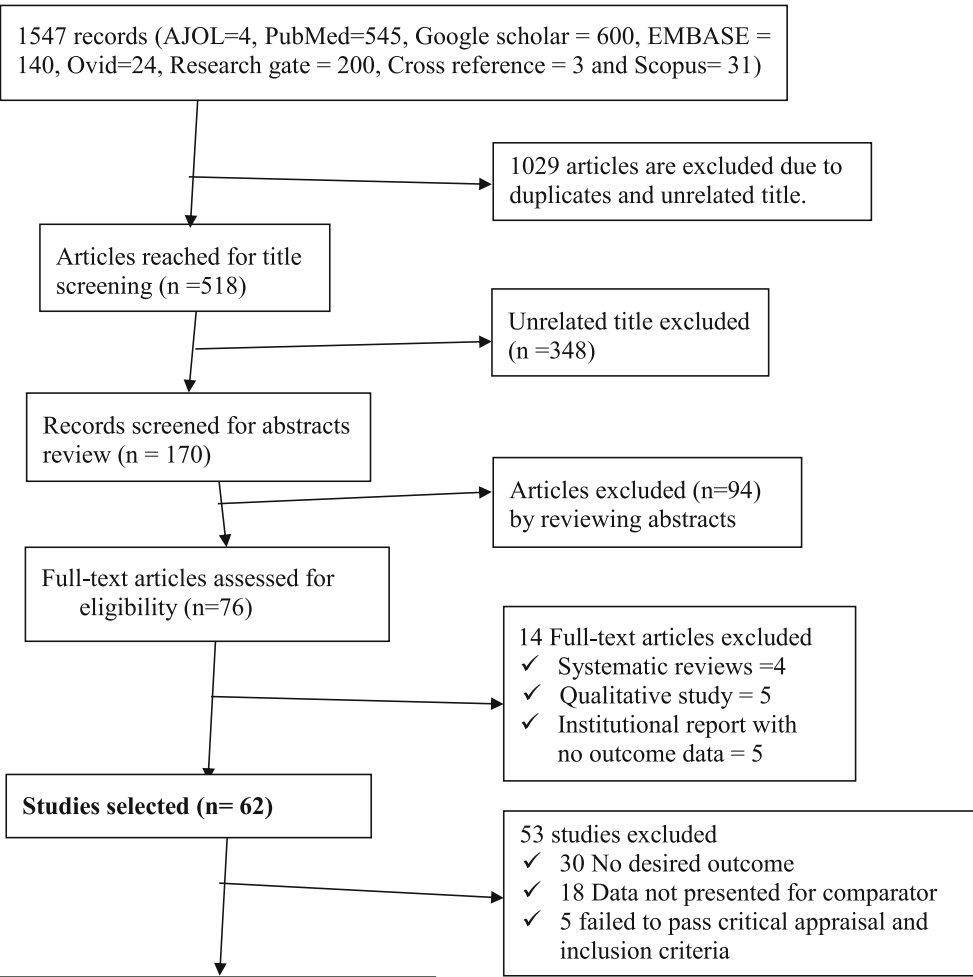

9 studies are systematically reviewed

Fig. 1 flow chart of study selected 
Table 1 summary of included studies

\begin{tabular}{|c|c|c|c|c|c|}
\hline Author & Set up & Study design & Outcome measure & Proportion for MWHs users & $\begin{array}{l}\text { Proportion for non MWHs } \\
\text { users }\end{array}$ \\
\hline \multirow{6}{*}{$\begin{array}{l}\text { J.M. Tumwine et al. } \\
1996 \text { [17] }\end{array}$} & \multirow[t]{6}{*}{ Zimbabwe } & \multirow[t]{6}{*}{ Retrospective cohort } & Stillbirth & $3 / 280$ & $16 / 773$ \\
\hline & & & Early neonatal mortality & $4 / 280$ & $7 / 773$ \\
\hline & & & Maternal death & $1 / 277$ & $3 / 757$ \\
\hline & & & Parity $=0$ & $89 / 280$ & $215 / 773$ \\
\hline & & & $1-4$ & $121 / 280$ & $367 / 773$ \\
\hline & & & $>=5$ & $70 / 280$ & $191 / 773$ \\
\hline \multirow[t]{6}{*}{ P.Millard et al. 1991 [18] } & \multirow[t]{6}{*}{ Zimbabwe } & \multirow[t]{6}{*}{ Comparative study } & Stillbirth & $9 / 486$ & $14 / 336$ \\
\hline & & & Early Neonatal mortality & $8 / 486$ & $14 / 336$ \\
\hline & & & Parity $=0$ & $123 / 486$ & $80 / 336$ \\
\hline & & & $1-3$ & $204 / 486$ & $137 / 336$ \\
\hline & & & $4-6$ & $121 / 486$ & $86 / 336$ \\
\hline & & & $>=7$ & $36 / 486$ & $30 / 336$ \\
\hline \multirow{3}{*}{$\begin{array}{l}\text { Lonkhuijzen Luc van et al. } \\
2003 \text { [19] }\end{array}$} & \multirow[t]{3}{*}{ Zambia } & \multirow[t]{3}{*}{ Retrospective cohort } & Maternal death & $0 / 218$ & $1 / 292$ \\
\hline & & & Parity $=0$ & $54 / 218$ & $31 / 292$ \\
\hline & & & $>6$ & $12 / 218$ & $8 / 292$ \\
\hline $\begin{array}{l}\text { Andemichael Ghirmay et al. } \\
2009 \text { [20] }\end{array}$ & Eritrea & Before and after study & Maternal death & $0 / 866$ & $5 / 266$ \\
\hline $\begin{array}{l}\text { Jody R Lori et al. } \\
2013 \text { [21] }\end{array}$ & Liberia & Prospective cohort & Maternal death & $3 / 248$ & $12 / 255$ \\
\hline \multirow{7}{*}{$\begin{array}{l}\text { Singh Kavita et al. } \\
2017 \text { [22] }\end{array}$} & \multirow[t]{7}{*}{ Malawi } & \multirow[t]{7}{*}{ Cross sectional } & Stillbirth & $3 / 255$ & $1 / 287$ \\
\hline & & & Parity $=1$ & $115 / 249$ & $104 / 288$ \\
\hline & & & $2-3$ & $73 / 249$ & $112 / 288$ \\
\hline & & & $>=4$ & $61 / 249$ & $68 / 288$ \\
\hline & & & Age $=15-19$ & $62 / 259$ & $45 / 288$ \\
\hline & & & $20-34$ & $164 / 259$ & $216 / 288$ \\
\hline & & & $>=35$ & $33 / 259$ & $26 / 288$ \\
\hline \multirow[t]{2}{*}{ Poovan Pia et al. 1990 [23] } & \multirow[t]{2}{*}{ Ethiopia } & \multirow[t]{2}{*}{ Retrospective cohort } & Maternal death & $0 / 142$ & $13 / 635$ \\
\hline & & & Stillbirth & $4 / 142$ & $161 / 635$ \\
\hline \multirow[t]{5}{*}{ J Kelly et al. 2010 [24] } & \multirow[t]{5}{*}{ Ethiopia } & \multirow[t]{5}{*}{ Retrospective cohort } & Maternal death & $6 / 6805$ & $187 / 17343$ \\
\hline & & & Stillbirth & $120 / 6805$ & $3316 / 17343$ \\
\hline & & & Parity $=0$ & $193 / 615$ & $525 / 1099$ \\
\hline & & & $1-3$ & $294 / 615$ & $366 / 1099$ \\
\hline & & & $>=4$ & $118 / 615$ & $177 / 1099$ \\
\hline \multirow{3}{*}{$\begin{array}{l}\text { D.Chandramohan et al. } \\
1994 \text { [25] }\end{array}$} & \multirow[t]{3}{*}{ Zimbabwe } & \multirow[t]{3}{*}{ Retrospective cohort } & Maternal death & $1 / 1573$ & $2 / 2915$ \\
\hline & & & Primiparas & $661 / 1573$ & $1108 / 2915$ \\
\hline & & & Parity $>6$ & $110 / 1573$ & $146 / 2915$ \\
\hline
\end{tabular}

methodological validity. It is appraised by appraisal instruments from the Joanna Briggs institute meta-analysis of statistical assessment and review instrument (JBI-MAStARI) (Additional file 1).

\section{Study outcomes}

Primary outcomes

Maternal death

Stillbirth
Secondary outcomes

Neonatal mortality

Parity

Assessment of quality of evidence across studies

Grade Pro software (Grade Pro 2016) is used to measure the quality across studies and to summarize findings. It has four levels: high, moderate, low or very low. Observational studies were categorized as low quality. But can 
Table 2 Quality assessment and summary the findings for the primary outcomes in developing countries

\begin{tabular}{|c|c|c|c|c|c|}
\hline \multirow[t]{2}{*}{ Outcomes } & \multirow{2}{*}{$\begin{array}{l}\text { № of participants } \\
\text { (studies) }\end{array}$} & \multirow{2}{*}{$\begin{array}{l}\text { Quality of } \\
\text { the } \\
\text { evidence } \\
\text { (GRADE) }\end{array}$} & \multicolumn{3}{|c|}{ Anticipated absolute effects } \\
\hline & & & Risk with MWH & Risk with Non MWH & Risk difference with MWH \\
\hline Maternal death & 32,592 (7 observational studies) & $\begin{array}{l}\oplus \oplus \oplus O \\
\text { MODERATE }\end{array}$ & $\begin{array}{l}1 \text { per } 1000 \\
(11 / 10,129)\end{array}$ & $\begin{array}{l}10 \text { per } 1000 \\
(223 / 22,463)\end{array}$ & $\begin{array}{l}9 \text { fewer per } 1000 \\
\text { (10 fewer to } 8 \text { fewer) }\end{array}$ \\
\hline Stillbirth & 27,342 (5 observational studies) & $\begin{array}{l}\oplus \oplus \oplus O \\
\text { MODERATE }\end{array}$ & $\begin{array}{l}17 \text { per } 1000 \\
(139 / 7968)\end{array}$ & $\begin{array}{l}181 \text { per } 1000 \\
(3508 / 19374)\end{array}$ & $\begin{array}{l}164 \text { fewer per } 1000 \\
\text { (166 fewer to } 159 \text { fewer) }\end{array}$ \\
\hline
\end{tabular}

GRADE Working Group grades of evidence

High quality: We are very confident that the true effect lies close to that of the estimate of the effect

Moderate quality: We are moderately confident in the effect estimate: The true effect is likely to be close to the estimate of the effect, but there is a possibility

that it is substantially different

Low quality: Our confidence in the effect estimate is limited: The true effect may be substantially different from the estimate of the effect

Very low quality: We have very little confidence in the effect estimate: The true effect is likely to be substantially different from the estimate of effect

be upgraded to moderate quality depending on the types of studies and factors that can increase the quality level. The factors that increase the levels are: large effect, if all plausible confounding would lead to an underestimation of the effect and if there is a dose-response gradient.

\section{Data extraction}

We extracted results of above-mentioned outcomes using data extraction tool from JBI-MAStARI (Additional file 1). All results were taken out by two independent reviewers to avoid extraction error.

\section{Data analysis}

Review Manager 5 is used for statistical analysis and Grade Pro software (Grade Pro 2016) is used to produce a summarized findings. Random-effect meta-analysis was performed to pool the odds ratio (OR) of the outcomes of maternal death and stillbirth. The assumption for random effect meta-analysis is from a range of populations in which the effect size varies and our goal is to summarize this range of effects. The conditions of the fixed effect model are not met, since the true effect size for all studies is identical, and the only reason the effect size varies between studies is random error. Each study is estimating an effect size for its unique population, and so each must be given appropriate weight in the analysis. We summarized the effect in terms of OR with their 95\% CI, risk difference (RD) and anticipated absolute effects. Forest plot containing OR, 95\% confidence intervals (CI), $P$ value, effect size, and, heterogeneity $\left(\mathrm{I}^{2}\right)$ were constructed. $P$ value $<=0.05$ was considered statistically significant. Sensitivity analysis or subgroup analysis is performed for meta-analysis incorporating more than two studies when the heterogeneity $\left(\mathrm{I}^{2}\right)$ is above $60 \%$ by removing outlier study. The forest plot is presented for each subgroup analysis.

\section{Result}

A total of 1547 articles were identified through databases searching. Of these, 1029 articles were excluded as duplicates and by observation of titles. Seventy six articles were identified for full text review, 67 of them are excluded due to not meeting the inclusion criteria. Nine studies were included in the review (Fig. 1).

\section{Summary of findings and description of included studies}

Nine studies are included to assess the primary and secondary outcomes. Parity is reported by 6 studies, but they reported in a different classification. Early neonatal mortality is reported by two studies. Age of mother is reported by only Singh Kavita et al. (Table 1).

The quality of our evidence across studies is moderate. All of studies are consistent that uses of MWHs have a better outcome in the prevention of maternal death and stillbirth. The result of anticipated absolute effect shows, the risk of maternal death with MWHs is 1 per 1000 live births. However the risk for pregnant females who don't use MWHs is 10 per 1000 live births. There is a great disparity in the occurrences of stillbirth among MWHs users and non-users. Among the users' risk of stillbirth is 17 per 1000 live births, but for non-users risk raises

Table 3 Quality assessment and summary the findings for the primary outcomes in Ethiopia

\begin{tabular}{|c|c|c|c|c|c|}
\hline \multirow{2}{*}{$\begin{array}{l}\text { Outcomes among MWH } \\
\text { and Non MWH users }\end{array}$} & \multirow{2}{*}{$\begin{array}{l}\text { № of participants } \\
\text { (studies) }\end{array}$} & \multicolumn{3}{|c|}{ Anticipated absolute effects ${ }^{*}(95 \%$ Cl) } & \multirow{2}{*}{$\begin{array}{l}\text { Quality of } \\
\text { the } \\
\text { evidence } \\
\text { (GRADE) }\end{array}$} \\
\hline & & Risk with Non MWH & Risk with $\mathrm{MWH}$ & Difference & \\
\hline Maternal death in Ethiopia & 24,925 (2 observational studies) & 11 per 1000 & $\begin{array}{l}0.86 \text { per } 1000 \\
(0 \text { to } 2)\end{array}$ & $\begin{array}{l}10.14 \text { fewer } \\
\text { ( } 9 \text { fewer to } 8 \text { fewer) }\end{array}$ & $\begin{array}{l}\oplus \oplus \oplus O \\
\text { MODERATE }\end{array}$ \\
\hline Stillbirth in Ethiopia & 24,925 (2 observational studies) & 65 per 1000 & $\begin{array}{l}18 \text { per } 1000 \\
(16 \text { to } 22)\end{array}$ & $\begin{array}{l}47 \text { fewer } \\
\text { (49 fewer to } 43 \text { fewer) }\end{array}$ & $\begin{array}{l}\oplus \oplus \oplus O \\
\text { MODERATE }\end{array}$ \\
\hline
\end{tabular}




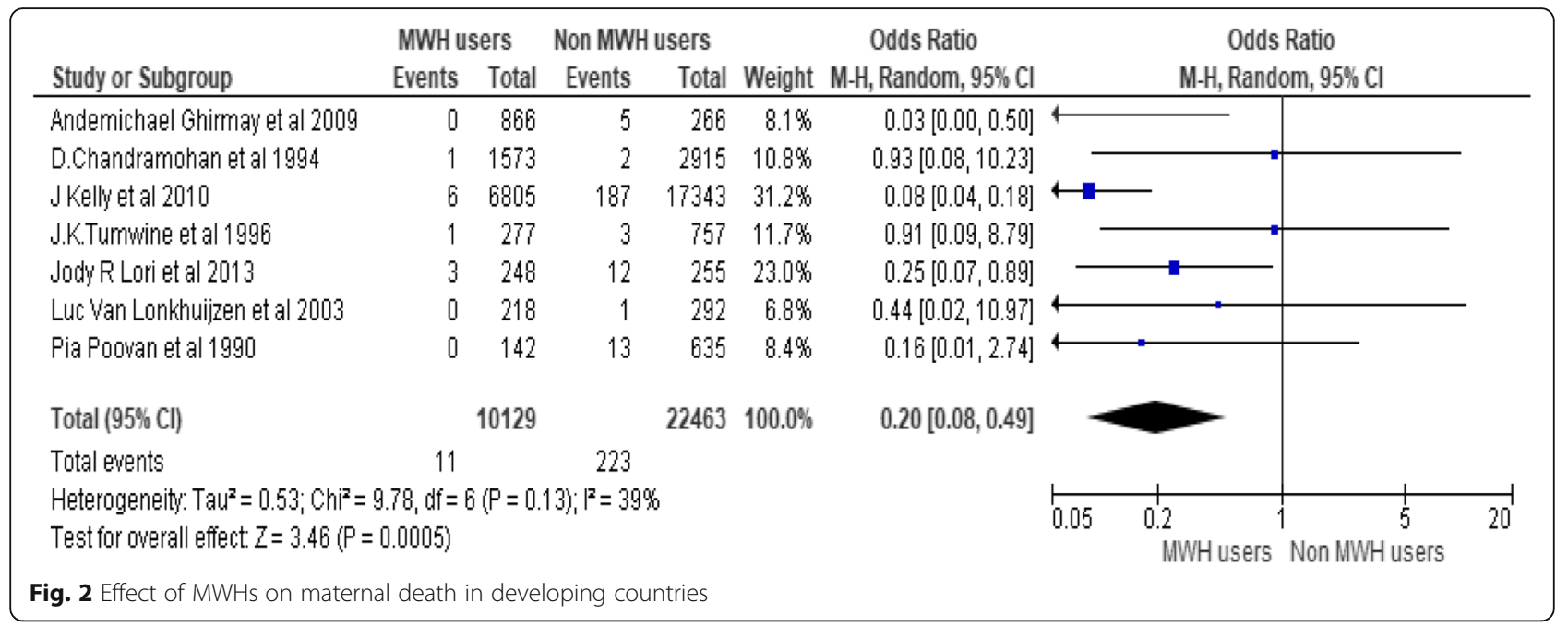

by more than ten times (181 per 1000 live births) (Table 2).

Anticipated absolute effects result for studies retrieved from Ethiopia shows maternal death among non MWHs users (11 per 1000 live births) is more than ten times higher than MWHs users (0.86 per 1000 live births). The risk of stillbirth is 3.6 times higher among MWHs non users than users (Table 3).

\section{Maternal death}

Effect of MWHs on maternal death in developing countries Seven studies including a total of 32,592 participants reported the occurrence of maternal death among $\mathrm{MWH}$ users and non-users. There are 11 maternal deaths out of 10,129 MWHs users and 223 maternal deaths out of $22,463 \mathrm{MWHs}$ non users. MWH user mothers are $80 \%$ less likely to die than non-users $(\mathrm{OR}=0.20,95 \% \mathrm{CI}$ $[0.08,0.49]), \mathrm{I}^{2}=39 \%,(P<0.00001)$ (Fig. 2).

\section{Effect of MWHs on maternal death in Ethiopia}

There are three studies conducted in Ethiopia incorporating a total of 24,925 participants (6947 MWH users and 17,978 non users). Only 6 maternal death occurred among users of $\mathrm{MWH}$ but, 200 deaths occurred among non-users. There is a $92 \%$ reduction of maternal death among MWHs users as compared to non-users $(\mathrm{OR}=$ 0.09, 95\% CI [0.04, 0.19]), $\mathrm{I}^{2}=0 \%,(P<0.00001)$ (Fig. 3).

\section{Stillbirth}

Effect of MWHs on stillbirth in developing countries

To assess effects of MWHs on stillbirth five studies are pooled, including 27,342 participants (7968 MWHs users and 19,374 non users). Occurrences of stillbirth among non-users are more than ten times as compared to non-users. There is $73 \%$ less occurrence of stillbirth among users $(\mathrm{OR}=0.27,95 \% \mathrm{CI}[0.09,0.82]), \mathrm{Chi}^{2}=$ 34.06, $\mathrm{df}=4(\mathrm{P}<0.00001) ; \mathrm{I}^{2}=88 \%$ (Fig. 4).

The heterogeneity is large $\left(\mathrm{I}^{2}=88 \%\right)$. In order to treat this heterogeneity, Subgroup analysis is conducted by removing outlier studies. The subgroup analysis is performed by removing the effect of J Kelly et al. 2010 and Pia Poovan et al. 1990 the heterogeneity becomes 29\%. However the odds ratio is not significant (Fig. 5).

\section{Effect of MWH on stillbirth in Ethiopia}

To observe the contribution of MWHs on reduction of stillbirth only two studies are included in the analysis of fixed effect meta-analysis. These studies incorporate a total of 24,925 participants. MWHs utilization contributes to the reduction of $83 \%$ stillbirth as compared to

\begin{tabular}{|c|c|c|c|c|c|c|c|c|c|c|}
\hline \multirow[b]{2}{*}{ Study or Subgroup } & \multicolumn{2}{|c|}{ MWH users } & \multicolumn{2}{|c|}{ Non MWH users } & \multirow[b]{2}{*}{ Weight } & \multirow{2}{*}{$\begin{array}{c}\text { Odds Ratio } \\
\text { M-H, Random, } 95 \% \mathrm{Cl}\end{array}$} & \multirow{2}{*}{\multicolumn{4}{|c|}{$\begin{array}{c}\text { Odds Ratio } \\
\text { M-H, Random, } 95 \% \mathrm{Cl}\end{array}$}} \\
\hline & Events & Total & Events & Total & & & & & & \\
\hline J Kelly et al 2010 & 6 & 6805 & 187 & 17343 & $92.4 \%$ & $0.08[0.04,0.18]$ & & - & & \\
\hline Pia Poovan et al 1990 & 0 & 142 & 13 & 635 & $7.6 \%$ & $0.16[0.01,2.74]$ & & & & \\
\hline Total $(95 \% \mathrm{Cl})$ & & 6947 & & 17978 & $100.0 \%$ & $0.09[0.04,0.19]$ & & & & \\
\hline Total events & 6 & & 200 & & & & & & & \\
\hline $\begin{array}{l}\text { Heterogeneity: } \operatorname{Tau}^{2}=0 \\
\text { Test for owerall effect: } z\end{array}$ & $\begin{array}{l}00 ; \mathrm{Chi}^{2}= \\
=6.17(\mathrm{P}\end{array}$ & $\begin{array}{l}0.21, \mathrm{dt} \\
0.0000\end{array}$ & $\begin{array}{l}f=1(P=0 \\
\text { 01) }\end{array}$ & (4); $i^{2}=0$ & & & 0.01 & 0.11 & $\begin{array}{cc}10 \\
\text { Non MWH users }\end{array}$ & 100 \\
\hline
\end{tabular}




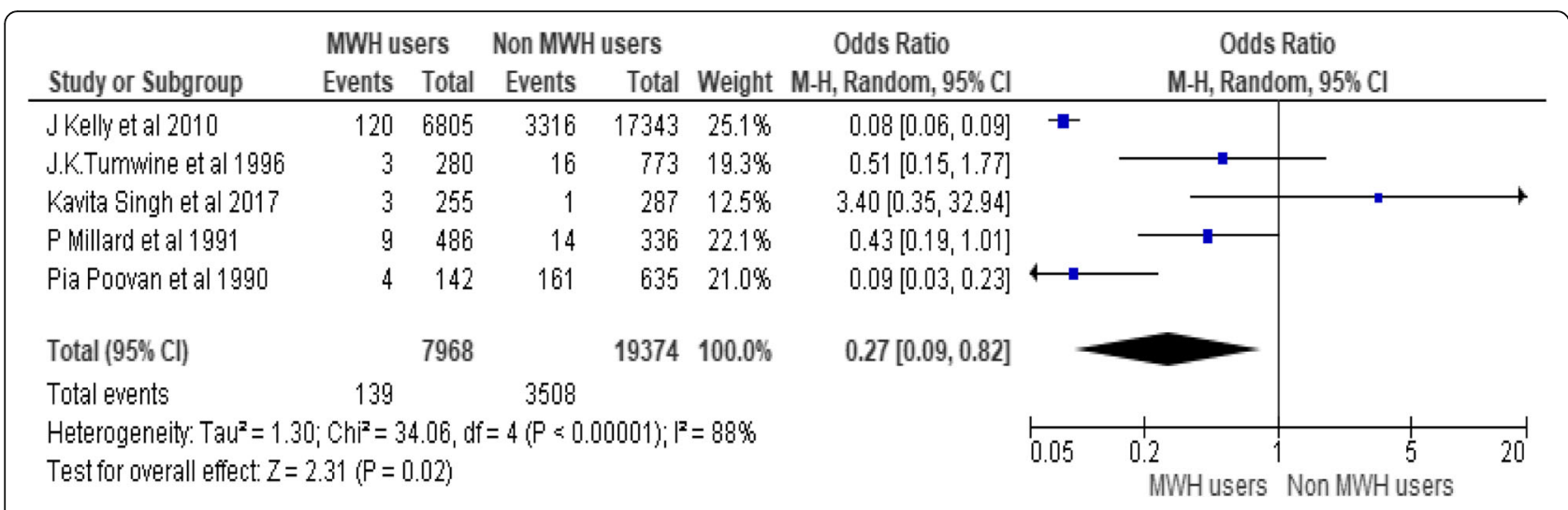

Fig. 4 Effect of MWHs on stillbirth in developing countries

non-users $(\mathrm{OR}=0.17,95 \% \mathrm{CI}[0.05,0.58]), \mathrm{Chi}^{2}=5.56$, $\mathrm{df}=1(P<0.02) ; \mathrm{I}^{2}=82 \%$ (Fig. 6$)$.

Even though the difference is significant the heterogeneity among the study is $82 \%\left(\mathrm{I}^{2}=82 \%\right)$. The reason for this heterogeneity is the number of participants included. JKelly et al. 2010 includes more than 20 times of participants than the other study. This makes JKelly et al. 2010 as outlier or vice versa.

\section{Secondary outcomes}

\section{Early neonatal mortality}

There are only two studies that include early neonatal mortality as an outcome in addition to the primary outcomes. They include a total of 1875 participants. Both of the studies are not in line whether MWH utilization reduces early neonatal mortality or not. Their aggregate effect is also not significant. But a higher proportion of early neonatal death occurred among non-users of MWHs than users (Fig. 7).

\section{Age of mother}

Age of mother is reported only by Singh Kavita et al. 2017. Most of users of MWHs (63.4\%) are mothers in the age group of 20-34. From females who are not users of MWHs 75\% of them are in between 20 and 34 (Table 4).

\section{Parity}

Six studies reported parity distribution of study participants. Each of them reported in different ways so unable to pool the results together. The two studies from Zimbabwe (by J.M.Tumwine et al. and P.Millard et al) shows when females' parity is $>=1$ they less likely utilize MWHs. But they most likely use when they don't have children (parity $=0$ ). In addition, study from Zambia (by Lonkhuijzen Luc van et al) shows females more likely use MWHs when they don't have children. In contrast to the above result from Zimbabwe, study from Ethiopia (by J.Kelly et al) shows females most likely use when they have children (parity > =1) (Table 4).

\section{Discussion}

$\mathrm{MWH}$ is one part of the strategy to boost uptake of maternal health services in developing countries by overcoming demand-side barriers. It avoids problems created due to long distance from health institutions. Since they can stay and await labour for high-risk

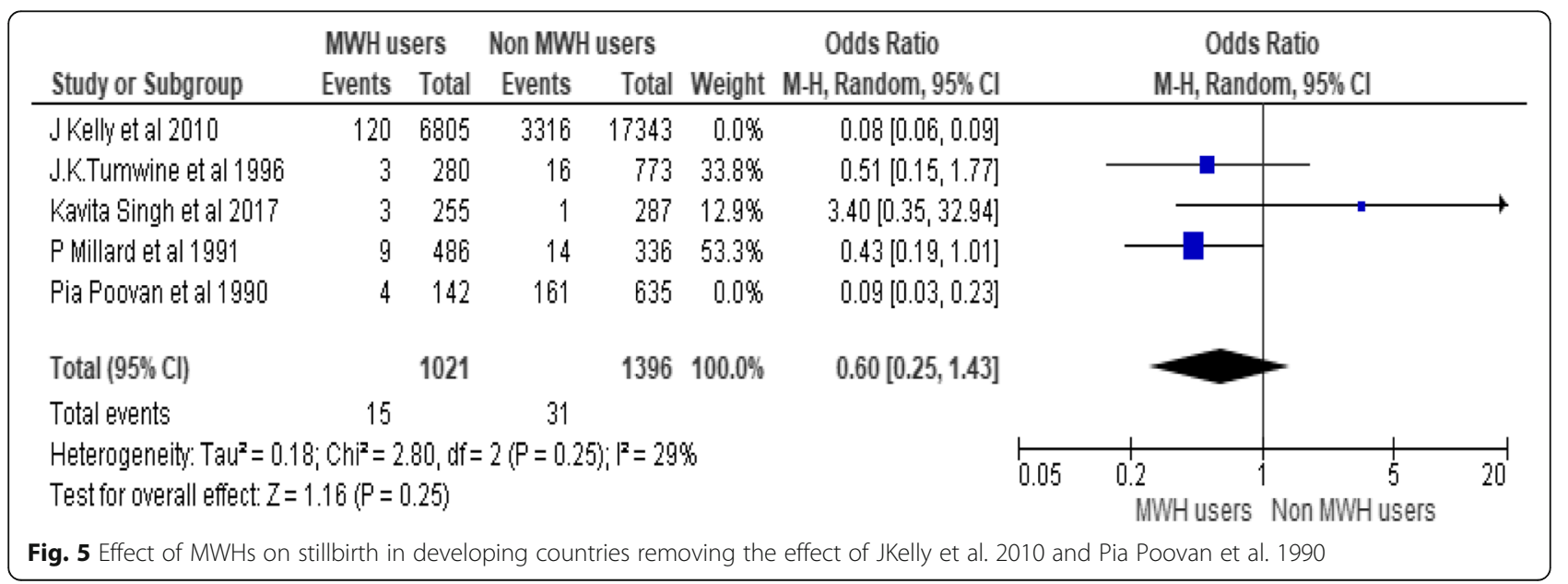




\begin{tabular}{|c|c|c|c|c|c|c|c|c|c|c|}
\hline \multirow[b]{2}{*}{ Study or Subgroup } & \multicolumn{2}{|c|}{ MWH users } & \multicolumn{2}{|c|}{ Non MWH users } & & \multirow{2}{*}{$\begin{array}{c}\text { Odds Ratio } \\
\text { M-H, Random, } 95 \% \mathrm{Cl}\end{array}$} & \multirow{2}{*}{\multicolumn{4}{|c|}{$\begin{array}{c}\text { Odds Ratio } \\
\text { M-H, Random, } 95 \% \mathrm{Cl}\end{array}$}} \\
\hline & Events & Total & Events & Total & Weight & & & & & \\
\hline J Kelly et al 2010 & 120 & 6805 & 1006 & 17343 & $58.4 \%$ & $0.29[0.24,0.35]$ & & & & \\
\hline Pia Poovan et al 1990 & 4 & 142 & 161 & 635 & $41.6 \%$ & $0.09[0.03,0.23]$ & 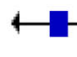 & & & \\
\hline Total (95\% Cl) & & 6947 & & 17978 & $100.0 \%$ & $0.17[0.05,0.58]$ & & & & \\
\hline Total events & 124 & & 1167 & & & & & & & \\
\hline $\begin{array}{l}\text { Heterogeneity: Tau }{ }^{2}=0 \\
\text { Test for owerall effect: } Z\end{array}$ & $\begin{array}{l}63 \mathrm{Chi}^{2}= \\
=2.86(\mathrm{P}=\end{array}$ & $\begin{array}{l}5.56, \mathrm{~d} \\
=0.004)\end{array}$ & $=1(P=0$ & $2 ; i_{1}^{2}=8$ & & & 0.05 & $\begin{array}{c}0.2 \\
\text { MWH users }\end{array}$ & $\begin{array}{c}\frac{1}{5} \\
\text { Non MWH users }\end{array}$ & 20 \\
\hline
\end{tabular}

pregnant women $[3,12]$. This meta-analysis depicts MWHs has a great contribution in decreasing maternal death and stillbirth rate in developing countries. The fixed effect meta-analysis shows MWHs have $80 \%$ contribution for reduction of maternal mortality among users $(\mathrm{OR}=0.20,95 \% \mathrm{CI}[0.08,0.49])$. This result might be underestimated since most of the time high-risk pregnant women are admitted in MWHs. The implication, for developing countries is that further expansion of MWHs an alternative best solution for rural areas.

Ethiopia reduced maternal mortality by $71.8 \%$ from 1250 in 1990 to 353 per 100,000 live births in 2015 .
Studies on health care institutions also show there is decreasing trend of maternal mortality $[6,13,14]$. Increasing accessibility of health services has its own contribution to the reduction. The meta-analysis depicts 91\% reduction of maternal death among MWHs users unlike non-users $(\mathrm{OR}=0.09,95 \% \mathrm{CI}[0.04,0.19)$. MWHs have their own contribution by decreasing second delay or by bridging high-risk pregnant women living far away from health institutions $[6,12]$.

The highest burden of stillbirth is found in low and middle- income countries (98\%). Sub-Saharan Africa and southern Asia regions accounts for $77 \%$ of stillbirth. Its

Table 4 maternal age and parity distribution among MWHs users and non-users

\begin{tabular}{|c|c|c|c|c|c|}
\hline Author & Set up & Study design & Outcome measure & Proportion for MWHs (\%) & Proportion for non MWHs (\%) \\
\hline \multirow{3}{*}{$\begin{array}{l}\text { J.M. Tumwine et al. } \\
1996 \text { [17] }\end{array}$} & \multirow[t]{3}{*}{ Rural Zimbabwe } & \multirow[t]{3}{*}{ Retrospective cohort } & Parity $=0$ & $89 / 280(31.8)$ & 215/773 (27.8) \\
\hline & & & $1-4$ & $121 / 280(43.2)$ & $367 / 773(47.5)$ \\
\hline & & & $>=5$ & $70 / 280(25)$ & 191/773 (24.7) \\
\hline \multirow{4}{*}{$\begin{array}{l}\text { P.Millard et al. } \\
1991 \text { [18] }\end{array}$} & \multirow[t]{4}{*}{ Rural Zimbabwe } & \multirow[t]{4}{*}{ Comparative study } & Parity $=0$ & $123 / 486(25.4)$ & $80 / 336(23.8)$ \\
\hline & & & $1-3$ & 204/486 (42) & $137 / 336(40.8)$ \\
\hline & & & $4-6$ & $121 / 486(25)$ & $86 / 336(25.6)$ \\
\hline & & & $>=7$ & $36 / 486(7.6)$ & 30/336 (8.8) \\
\hline \multirow{2}{*}{$\begin{array}{l}\text { Lonkhuijzen Luc van } \\
\text { et al. } 2003 \text { [19] }\end{array}$} & \multirow[t]{2}{*}{ Rural Zambia } & \multirow[t]{2}{*}{ Retrospective cohort } & Parity $=0$ & $54 / 218(24.8)$ & $31 / 292(10.6)$ \\
\hline & & & $>6$ & $12 / 218(5.5)$ & $8 / 292(2.7)$ \\
\hline \multirow{6}{*}{$\begin{array}{l}\text { Singh Kavita et al. } \\
\text { 2017 [22] }\end{array}$} & \multirow[t]{6}{*}{ Malawi } & \multirow[t]{6}{*}{ Cross sectional } & Parity $=1$ & $115 / 249(46.2)$ & $104 / 288(36.1)$ \\
\hline & & & $2-3$ & $73 / 249(29.3)$ & 112/288 (38.9) \\
\hline & & & $>=4$ & $61 / 249(24.5)$ & $68 / 288(23)$ \\
\hline & & & Age $=15-19$ & $62 / 259(23.9)$ & 45/288 (15.6) \\
\hline & & & $20-34$ & $164 / 259(63.4)$ & $216 / 288(75)$ \\
\hline & & & $>=35$ & $33 / 259(12.7)$ & 26/288 (9.4) \\
\hline \multirow[t]{3}{*}{ J Kelly et al. 2010 [24] } & \multirow[t]{3}{*}{ Ethiopia } & \multirow[t]{3}{*}{ Retrospective cohort } & Parity $=0$ & 193/615 (31.4) & $525 / 1099(47.8)$ \\
\hline & & & $1-3$ & 294/615 (47.8) & 366/1099 (33.3) \\
\hline & & & $>=4$ & 118/615 (19.2) & $177 / 1099(16.1)$ \\
\hline \multirow{2}{*}{$\begin{array}{l}\text { D.Chandramohan et al. } \\
1994 \text { [25] }\end{array}$} & \multirow[t]{2}{*}{ Ethiopia } & \multirow[t]{2}{*}{ Retrospective cohort } & Primiparas & $661 / 1573(42)$ & 1108/2915 (38) \\
\hline & & & Parity $>6$ & 110/1573 [7] & 146/2915 [5] \\
\hline
\end{tabular}




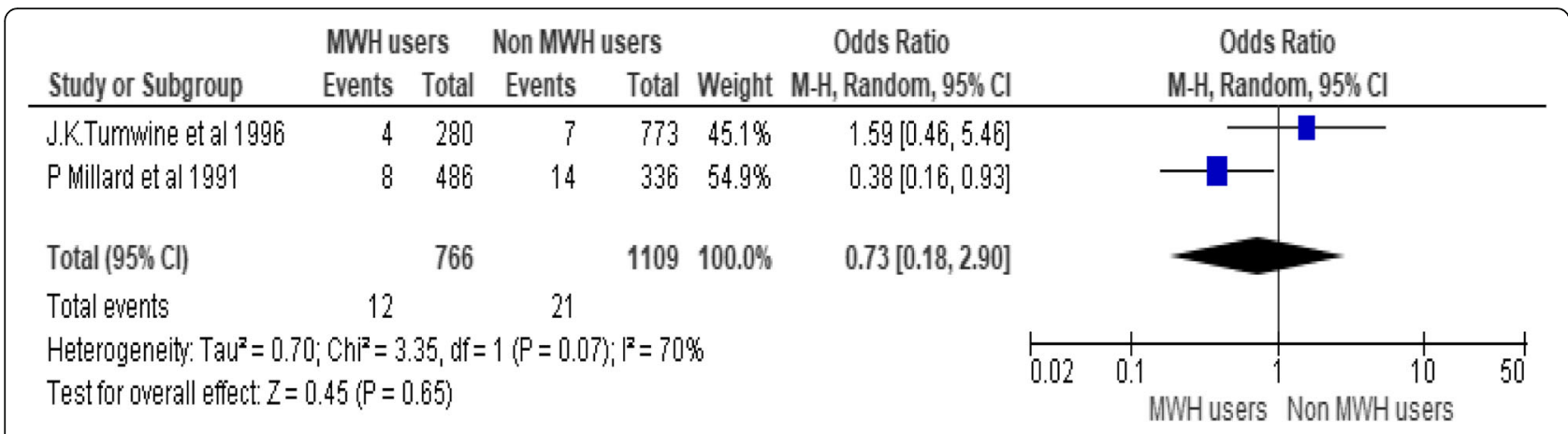

Fig. 7 Effect of MWHs on early neonatal mortality in developing countries

reduction is lowest in sub-Saharan Africa (1.4\%) [7]. The causes for the high rates of stillbirth is due to poor maternal health care services [15]. There is a great disparity on the occurrences of stillbirth among MWHs users and non-users. This meta-analysis tells us that MWHs have an amicable role to reduce stillbirth. There is $73 \%$ less occurrence of stillbirth among MWHs users (OR $=0.27,95 \% \mathrm{CI}$ $[0.09,0.82])$ as compared to non-users. This finding implies that, constructing MWHs or strengthening its construction as a strategy to reduce stillbirth is effective mode of interventions.

Ethiopia is the fifth country in the world by having 97, 000 stillbirths [7]. MWHs utilization contributes to the reduction of $83 \%$ of stillbirth unlike non-users $(\mathrm{OR}=$ $0.17,95 \%$ CI $[0.05,0.58])$. As above mentioned, MWHs are crucial as a prevention modalities.

Low and middle income countries contribute $99 \%$ of neonatal deaths; about half of them occur at home. The first week of life covers three fourth of death. The highest risk of death is on the first day of life [16]. There are only two studies pooled together. Study by P.Millard et al. shows MWHs use reduce early neonatal mortality. The other study is not significant. Their aggregate effect is not significant. But a higher proportion of early neonatal death occurred among non-users of MWHs than others.

These findings suggest that construction of maternity waiting home near health facility is one of the effective strategies to break phase II delays or transportation delays in developing countries.

\section{Limitation of study}

This systematic review and meta-analysis is conducted incorporating observational studies only. Literatures written by other than English is not included. Literatures included from Ethiopia in this review is conducted in only one place at different times. It does not represent the whole country. There might a possibility of publication bias since published literatures written in English is included.

\section{Conclusion}

Having the abovementioned limitation of the study: Maternity waiting home contributes almost $80 \%$ for the reduction of maternal death among users in developing countries and Ethiopia as per this review. Its contribution for reduction of stillbirth is good. More than $70 \%$ of stillbirth is reduced among the users. In Ethiopia MWHs contributes to a reduction of more than two third stillbirths among users. The effect of MWHs on early neonatal mortality among MWHs users and non-users is not significant. But, a higher proportion of deaths occur among non-users. The major implication of this review is MWHs are effective for the accomplishment of sustainable development goals related to maternal and child health. The authors recommend further review as a primary outcome to confirm whether MWHs is effective in reducing early neonatal death or not. In addition randomized controlled trial study is the gold standard method to prove the effectiveness of maternity waiting home.

\section{Additional file}

Additional file 1: This file contain Index and mesh terms, the search strategy used in different databases, critical appraisal formats, and data extraction format (DOCX $645 \mathrm{~kb}$ )

\section{Abbreviations \\ AOR: Adjusted odds ratio; Cl: Confidence interval; DHS: Demographic and health survey; EDHS: Ethiopian demographic and health survey; EPPI- Centre: Evidence for Policy and Practice Information; HTA: Health Technology Assessment; JBI- DSRIR: Joanna Briggs Institute Database of Systematic Reviews and Implementation Reports; JBI-MAStARI: Joanna Briggs institute meta-analysis of statistical assessment and review instrument; MWHs: Maternity waiting homes; OR: Odds ratio; SSA: Sub - Saharan Africa; WHO: World health organization \\ Funding \\ There was no funding for this study. The corresponding author had full access to all the data in the study, and had final responsibility for the decision to submit for publication.}

Availability of data and materials

The data is available when there is demand. 


\section{Author's contributions}

TLD did article searching, critical appraisal, data extraction, data analysis, and edited manuscript. BBB did article searching, critical appraisal, data extraction, data analysis, and edited manuscript. HKK did article searching, critical appraisal, data extraction, data analysis, and edited manuscript. TN did article searching, critical appraisal, data extraction, data analysis, and edited manuscript. All authors have read and approved the manuscript.

\section{Ethics approval and consent to participate}

not applicable.

\section{Consent for publication}

Not applicable.

\section{Competing interests}

We declare no competing interest.

\section{Publisher's Note}

Springer Nature remains neutral with regard to jurisdictional claims in published maps and institutional affiliations.

\section{Author details}

'Department of public health, Collage of Health Science, Mizan-Tepi University, Tepi, Ethiopia. ${ }^{2}$ Department of midwifery, Collage of Health Science, Wollega University, Nekemte, Ethiopia. ${ }^{3}$ Mizan Teferi, Ethiopia.

Received: 23 February 2018 Accepted: 24 September 2018 Published online: 01 October 2018

\section{References}

1. WHO. Maternity waiting homes: a review of expereinces. Geneva: WHO; 1996. Available from: http://www.who.int/reproductivehealth/publications/ maternal_perinatal_health/MSM_96_21/en/.

2. WHO. Maternity waiting homes: a review of expereinces. Geneva:WHO; 1996.

3. $\mathrm{WHO}$. WHO recommendations on health promotion interventions for maternal and newborn health. Geneva: WHO; 2015. p. 24-7.

4. Legese T, Abdulahi M, Dirar A. Risk factors of maternal death in Jimma University specialized Hospital : a matched case control study. Am J Public Heal Res. 2016:4(4):120-7.

5. Vermeiden T, Stekelenburg J. Maternity waiting homes as part of an integrated program for maternal and neonatal health improvements: Women's lives are worth saving. J Midwifery Womens Health United States. 2017 Mar;62(2):151-4.

6. WHO, UNICEF, eUNFPA, World Bank Group the UNPD. Trends in maternal mortality 1990-2015. Geneva:WHO; 2015

7. Blencowe H, Cousens S, Jassir FB, Say L, Chou D, Mathers C, et al. National, regional, and worldwide estimates of stillbirth rates in 2015, with trends from 2000 : a systematic analysis. Lancet Glob Heal [Internet]. 2015;4(2):e98108. Available from: https://doi.org/10.1016/S2214-109X(15)00275-2.

8. EWEC Technical Content Workstream working Group on ending preventable maternal and newborn mortality and stillbirths. Ending Preventable Maternal and Newborn Mortality and Stillbirths. 2015.

9. WHO. The Global Strategy for Women's and Children's and Adolescents' Health (2016-2030): Survive, Thrive, Transform. United Nations. 2015;1:1-108. Available from: www.unaids.org/sites/default/files/media.../ EWECGSMonitoringReport2018 en.pdf. Accessed April 2016

10. Buser JM, Lori JR. Newborn Outcomes and Maternity Waiting Homes in Low and Middle-Income Countries: A scoping review. Matern child health J. New York: Springer; 2016

11. van Lonkhuijzen L, Stekelenburg J van RJ. Maternity waiting facilities for improving maternal and neonatal outcome in low-resource countries ( Review ). Cochrane Database Syst Rev. 2009;3:D006759.

12. Elmusharaf $K$, Byrne $E$, Donovan DO. Strategies to increase demand for maternal health services in resource-limited settings : challenges to be addressed. BMC Public Health. 2015:15(870):1-10.

13. Legese T, Mulatu K, Kahsay T. Trends and determinants of maternal mortality in Mizan-Tepi University teaching and Bonga general hospital from 2011 - 2015 : a case control study. Heal Sci J. 2016;10(5):1-8.
14. Legesse T, Abdulahi M, Dira A. Trends and causes of maternal mortality in Jimma University specialized hospital, Southwest Ethiopia : a matched case - control study. Int J Women's Heal. 2017;9(2017):307-13.

15. Kiguli J, Munabi IG, Ssegujja E, Nabaliisa J, Kabonesa C, Kiguli S, et al. Stillbirths in sub-Saharan Africa : unspoken grief. Lancet [Internet]. Elsevier Ltd; 2016;6736(15):10-11. Available from: https://doi.org/10.1016/S01406736(15)01171-X.

16. Lawn JE, Cc A, Kinney M, Sibley L, Carlo WA, Paul VK, et al. Two million intrapartum-related stillbirths and neonatal deaths: Where, why, and what can be done? Int J Gynecol Obstet [Internet]. International Federation of Gynecology and Obstetrics; 2009;107(2009):S5-19. Available from: https:// doi.org/10.1016/j.ijgo.2009.07.016

17. Tumwine JK, Dungare PS. Maternity waiting shelters and pregnancy outcome : experience from a rural area in Zimbabwe. Ann Trop Paediatr [Internet] 1996;16(1):55-59. Available from: https://doi.org/10.1080/02724936. 1996.11747804

18. Millard P, Balley J, Hanson J. Antenatal village stay and pregnancy outcome in rural Zimbabwe. Cent Afr J Med. 1991;37(I):1-4.

19. Luc van Lonkhuiyzen, Margreet Stegeman, Rebecca Nyirongo Van Roosmalen J. Use of Maternity Waiting Home in Rural Zambia. Africa J Reprod Heal [Internet]. 2003 [cited 2014 Jan 1];7(1):32-36. Available from: https://www.ncbi.nlm.nih.gov/pubmed/12828140

20. Andemichael G, Haile B, Kosia A, Mufunda J. Maternity waiting homes : a panacea for maternal / neonatal conundrums in Eritrea. J Eritrean Med Assoc. 2009;4(1):18-21.

21. Lori JR, Munro ML, Rominski S, Williams G, Dahn BT, Boyd CJ, et al. Maternity waiting homes and traditional midwives in rural Liberia. Int J Gynecol Obstet [Internet]. International Federation of Gynecology and Obstetrics; 2013;123(2):114-118. Available from: https://doi.org/10.1016/j.ijgo.2013.05. 024

22. Singh K, Speizer I, Kim ET, Lemani C, Phoya A, Foundation MG. Reaching vulnerable women through maternity waiting homes in Malawi. Int J Gynecol Obstet. 2017;136(August 2016):91-7.

23. Poovan P, Kifle F, Kwast BE. A maternity waiting home reduces obstetric catastrophes. World Health Forum. Switzerland. 1990;11(4):440-5.

24. Kelly J, Kohls E, Poovan P, Schiffer R, Redito A, Winter $H$, et al. The role of a maternity waiting area (MWA) in reducing maternal mortality and stillbirths in high-risk women in rural Ethiopia. BJOG England. 2010;117(11):1377-83.

25. Chandramohan D, Cutts F, Chandra R. Effects of a maternity waiting home on adverse maternal outcomes and the validity of antenatal risk screening Int J Gynaecol Obstet United States. 1994 Sep;46(3):279-84.

Ready to submit your research? Choose BMC and benefit from:

- fast, convenient online submission

- thorough peer review by experienced researchers in your field

- rapid publication on acceptance

- support for research data, including large and complex data types

- gold Open Access which fosters wider collaboration and increased citations

- maximum visibility for your research: over $100 \mathrm{M}$ website views per year

At $\mathrm{BMC}$, research is always in progress.

Learn more biomedcentral.com/submissions 